\title{
VIABILIDADE ECONÔMICA DE REFLORESTAMENTOS EM ÁREAS LIMÍTROFES DE PEQUENAS PROPRIEDADES RURAIS NO MUNICÍPIO DE SÃO JOSÉ DOS PINHAIS - PR
}

\author{
Ricardo Anselmo Malinovski*, Ricardo Berger**, Ivan Crespo Silva***, \\ Rafael Alexandre Malinovski****, Ricardo Marques Barreiros***** \\ *Eng. Florestal, M.Sc., UNESP - ricardo@itapeva.unesp.br \\ **Eng. Florestal, Dr., Depto. de Economia Rural e Extensão, UFPR - berger@floresta.ufpr.br \\ ***Eng. Florestal, Dr., Depto. de Ciências Florestais, UFPR - ivan@floresta.ufpr.br \\ ****Eng. Florestal, M.Sc., Klabin - ralexandre@klabin.com.br \\ *****Eng. Florestal, Dr., UNESP - rmbarreiros@itapeva.unesp.br \\ Recebido para publicação: 28/11/2005 - Aceito para publicação: 05/06/2006
}

\begin{abstract}
Resumo
Esta pesquisa constituiu-se de uma análise da atividade florestal em pequenas propriedades rurais no município de São José dos Pinhais (PR), propondo a implantação de essências florestais nas áreas limítrofes dessas propriedades. Procedeu-se a uma avaliação econômica envolvendo as espécies bracatinga, erva-mate, eucalipto e pinus, visando o plantio nas bordaduras das propriedades. Realizou-se um planejamento para um ciclo de 21 anos para todas as espécies, com o objetivo de comparar o retorno econômico da atividade. Para análise econômica das culturas, utilizaram-se os critérios do Valor Presente Líquido (VPL), da Razão Benefício/Custo (RB/C) e da Taxa Interna de Retorno (TIR). Os resultados obtidos mostram que predominam no município propriedades com dimensões entre 0,1 e 15 ha e que a erva-mate é a cultura de melhor desempenho econômico para o plantio nas áreas limítrofes, seguida do pinus.

Palavras-chave: Pequenas propriedades; áreas de bordaduras; essências florestais.
\end{abstract}

\begin{abstract}
Economic viability of reforestations in bordering areas in small properties in the county of São José dos Pinhais-PR. The main subject of this work was to evaluate the actual woodland situation of the rural small properties located in São José dos Pinhais district in order to suggest economics suitable trees species for implementation on their boundaries. Some species as bracatinga, erva-mate, eucalypt and pines had an economic evaluation in order to decide about its application on the properties boundaries. At 21 years life cycle planning was developed to find out each economic return rate. The economic analysis was performed by the Net Present Value (NPV), the Benefit/Cost Rate, and the Internal Return Rate (IRR) criteria. The results gained shown that: properties size range is from 0,1 to 15 ha and Erva-mate cultivation presented the best economic option for the boundaries application followed by pines culture.

Keywords: rural properties; boundaries areas; forest essences.
\end{abstract}

\section{INTRODUÇ̃̃O}

A expansão e modernização da agricultura brasileira, apesar de contribuírem significativamente para o aumento da produção e da produtividade agrícola e pecuária, provocaram grande redução da cobertura florestal e diminuição da oferta de produtos florestais, causando alterações no funcionamento dos ecossistemas naturais, especialmente no que se refere ao desequilíbrio no regime das águas e do clima.

A sociedade brasileira necessita cada vez mais de soluções que permitam a expansão da produção agrícola e de produtos florestais, associados à preservação ambiental, além de alternativas de emprego e renda, particularmente para os pequenos e médios produtores rurais (RODIGHERI, 1997). Diante desse panorama, torna-se importante a adoção de medidas que assegurem o aumento da oferta de 
produtos agrícolas e florestais, acompanhadas da conservação e recuperação dos solos, da despoluição da água e da preservação da floresta nativa remanescente.

Um dos principais problemas encontrados na definição de uma política florestal voltada aos anseios e às necessidades dos produtores rurais é a falta de conhecimento sobre as relações da cobertura florestal com as demais atividades de subsistência, socioeconômicas, culturais, ecológicas e políticas, entre outras, que participem das decisões dos agricultores. Tal fato tem concorrido para a diminuição acelerada das florestas e o êxodo do homem do meio rural (ANGELO, 1999).

O reflorestamento em pequenas e médias propriedades rurais é de interesse público. Ele é uma fonte de renda, contribui para evitar o êxodo rural e o desemprego e, simultaneamente, possibilita inúmeros e imprescindíveis benefícios ambientais. Portanto, uma pequena ou média propriedade rural bem planejada deve sempre possuir uma área para reflorestamento (JANKOWSKY; GALVÃO, 2000).

A cobertura florestal em áreas rurais traz consigo benefícios diretos e indiretos, tais como proteção do solo contra erosão, aumento da retenção da água no solo, geração de empregos e melhoria da distribuição de renda, contribuindo, assim, para uma melhoria de ordem social e econômica dos produtores e de suas famílias.

Os pequenos produtores rurais do município de São José dos Pinhais, em sua maioria, são produtores de hortifrutigranjeiros, e são raras as propriedades que possuem reflorestamento. Com este trabalho, procurou-se estudar alternativas para inserção de essências florestais na propriedade rural, com o objetivo de evidenciar o potencial de aumento de renda destes produtores.

\section{Objetivo}

O objetivo deste trabalho foi avaliar a rentabilidade econômica dos plantios de pinus (Pinus taeda L.), eucalipto (Eucalyptus dunnii Maiden), bracatinga (Mimosa scabrella Benth) e erva-mate (Ilex paraguariensis A. St.-Hil.) em áreas limítrofes de pequenas propriedades rurais no município de São José dos Pinhais (PR).

\section{REVISÃO DE LITERATURA}

\section{Aspectos agrários do município de São José dos Pinhais}

Segundo o relatório da EMATER (2001), o município possui 3.950 propriedades rurais, classificadas como:

- $\quad$ produtor simples de mercadoria com área menor que 15 ha (PSM1) - 1383;

- $\quad$ produtor simples de mercadoria com área menor que 30 ha (PSM2) - 1185;

- $\quad$ produtor simples de mercadoria com área menor que 50 ha (PSM3) - 790;

- empresário familiar com área entre 50 e 100 ha (EF) - 395;

- $\quad$ empresário rural com área superior a 100 ha (ER) - 197.

Mais de 35 \% são produtores rurais que possuem área menor que 15 ha, enquanto outros, cerca de $30 \%$, possuem propriedades entre 15 e 30 ha. Isso mostra a realidade municipal no campo, onde prevalece o minifúndio.

Como a EMATER é o órgão de extensão rural mais atuante no município, a presente pesquisa considerou os dados dessa entidade para efeito de comparação.

\section{Fatores que afetam a cobertura florestal}

Vários são os fatores que afetam a cobertura florestal: as culturas itinerantes, o desmatamento para aumentar os pastos, o crescimento populacional, os incêndios criminosos, a necessidade de lenha, madeira para construções, aclimatação de vegetais e animais que se tornam nocivos ao ambiente, guerras, poluição ambiental, necessidade de madeira para fins industriais, fatores econômicos e políticos, entre outros (BIGARELLA, 1974).

No Brasil, a redução acelerada da cobertura florestal tem sido motivo de preocupação crescente de diversos segmentos sociais empenhados em minimizar os efeitos do desmatamento e em promover a conservação dos solos e demais recursos naturais. Segundo Verdolin (1984), esse desmatamento deve-se ao incremento da população brasileira e às suas necessidades cada vez maiores de produtos de origem agrícola e florestal, que criam uma demanda de terras nas várias regiões do país. 
De acordo com Vinade et al. (1980), a derrubada completa por ocasião das roçadas é o modo normal de exploração em algumas regiões do estado do Rio Grande do Sul. Os mesmos autores verificaram que a alegação da necessidade de aumentar as áreas de pastagem e de plantio agrícola tem sido a causa da redução da cobertura florestal no referido estado. Segundo Santos Filho (1980), a causa do desmatamento foi a implantação da agricultura e o aproveitamento comercial da madeira. A constante busca de áreas para novas plantações, a expansão da cultura cafeeira em direção ao norte do estado e, mais recentemente, a cultura da soja, principalmente na região oeste, são os principais fatores do rápido desaparecimento da cobertura florestal paranaense.

Segundo Hosokawa e Mendes (1984), a devastação florestal no Sul e Sudoeste do Brasil teve seu ápice nas décadas em que algumas culturas agrícolas revelaram um caráter de grande expressão na economia mundial, como é o caso do café, da soja, do trigo e da cana-de-açúcar, tanto em São Paulo como no Paraná.

\section{Plantios florestais em pequenas propriedades rurais}

Tendo em vista o significado das pequenas propriedades na produção de gêneros alimentícios de primeira necessidade e dos problemas com os quais se defrontam, ou seja, baixos níveis de renda, desemprego, subemprego e uma certa carência no que diz respeito à conservação do ecossistema, a questão geral que se levanta é de como aumentar a renda, o nível de emprego e incentivar a conservação dos solos nas pequenas propriedades rurais (ANGELO, 1987).

Segundo Barbosa (1978), alguns estudos empíricos indicam que tecnologias alternativas, incluindo novos produtos, podem apresentar grande potencial para a geração de níveis mais altos de renda. No entanto, um ponto importante a ser observado é que as novas tecnologias devem ser compatíveis com os recursos dos pequenos produtores e simples para serem adotadas. Quanto aos novos produtos, restrições de demanda podem impedir sua produção. Além disso, em casos de culturas perenes ou de longo período de espera, a subsistência dos agricultores tem de ser garantida.

De acordo com Ceccon (1991), o enfoque da pequena e média propriedade na pesquisa florestal brasileira tem sido pouco praticado. O escasso interesse por esse assunto talvez seja resultado de uma má compreensão do papel dessas propriedades no manejo e na produção florestal.

A adoção de sistemas agroflorestais na região Sul ainda é inexpressiva. Segundo Schreiner (1994), as grandes empresas madeireiras, em fins da década de 70 e princípios da de 80 , chegaram a rejeitar incentivos governamentais em favor da agrossilvicultura, alegando, entre outras limitações, a dificuldade de colheita mecânica das culturas agrícolas, falta de informações sobre efeitos de defensivos agrícolas nas árvores, riscos apresentados por algumas espécies agrícolas, etc. A introdução de animais no sub-bosque foi até certo ponto aceita, todavia, apenas para mantê-lo limpo, e não para formação de um sistema.

Giacomini et al. (1988) estudaram a questão do reflorestamento na pequena propriedade como uma opção energética para o meio rural, na região noroeste do Rio Grande do Sul. Os autores encontraram benefícios intangíveis no caso do reflorestamento, como: a) enriquecimento dos ambientes; b) preservação da flora e fauna nativas; c) purificação do ar; d) conservação do solo, evitando a erosão e o assoreamento dos cursos d'água.

\section{Plantio em linha de árvores com potencial madeireiro}

O plantio de espécies arbóreas em linha nas propriedades rurais, no mundo todo, é considerado como uma modalidade potencial de sistema agroflorestal, devido basicamente à possibilidade de haver combinações com cultivos agrícolas e pastagens naturais ou cultivadas. Apresenta como principal vantagem o fornecimento de madeira para serraria ou postes, ocupando geralmente somente áreas subutilizadas, como os limites internos e externos da propriedade rural. Também proporciona diversos benefícios ecológicos e diversificação da produção, além de contribuir para a melhoria do ambiente e da paisagem rural (BEER, 1994).

\section{Espécies potenciais para reflorestamento em áreas limítrofes nas propriedades rurais no município de São José dos Pinhais \\ Bracatinga}

A bracatinga, espécie arbórea, heliófila, da família Mimosaceae, ocorre na região sul do Brasil, geralmente em solos com textura argilosa. Segundo Rotta e Oliveira (1981), sua área mais expressiva e 
contínua de ocorrência natural situa-se entre as latitudes $23^{\circ} 50^{\mathrm{TM}}$ e $29^{\circ} 40^{\mathrm{TM}} \mathrm{S}$ e longitude de $48^{\circ} 50^{\mathrm{TM}} \mathrm{W}$ até $53^{\circ} 50^{\mathrm{TM}} \mathrm{W}$, nos estados de Minas Gerais (sul), São Paulo (leste e sul), Paraná (sul e centro-sul), Santa Catarina (leste e sul) e Rio Grande do Sul (nordeste), preferencialmente em altitudes de $400 \mathrm{~m}$ a $1800 \mathrm{~m}$.

Grandes superfícies da área metropolitana de Curitiba e outras, principalmente nos estados do Paraná e Santa Catarina, estão reflorestadas com bracatinga, formando densas associações em que cerca de $61 \%$ correspondem a bracatinga e o restante engloba mais de 80 espécies (BAGGIO, 1994). Vistos de cima, os bracatingais parecem constituir agrupamentos puros, uma vez que, nas áreas de cultivo, o dossel é exclusivamente formado pelas copas dessa árvore (CARVALHO, 1981).

A bracatinga é considerada uma das espécies de crescimento inicial mais rápido no sul do Brasil. Árvore perenifólia, normalmente com 10 a $18 \mathrm{~m}$ de altura e 20 a $30 \mathrm{~cm}$ de DAP, pode atingir até $29 \mathrm{~m}$ de altura e $50 \mathrm{~cm}$ de DAP. $\mathrm{O}$ tronco pode ser alto e esbelto em maciços, ou curto e ramificado em árvores isoladas. O fuste desenvolve-se até $15 \mathrm{~m}$ de comprimento e o diâmetro da copa pode variar de $1,5 \mathrm{~m}$, em povoamento, até $10 \mathrm{~m}$ em árvores isoladas (ROTTA; OLIVEIRA, 1981). Alguns povoamentos implantados por mudas têm alcançado produtividade de até $36 \mathrm{~m}^{3} / \mathrm{ha}$.ano ou $55 \mathrm{st} / \mathrm{ha}$.ano com casca, sob regeneração artificial (AHRENS, 1981).

Reichmann Neto (1981) considera que a bracatinga é uma espécie promissora no fornecimento de matéria-prima para a produção de carvão, lenha, aglomerados, construção civil, bem como para recuperação e conservação de solos, já que esta árvore tem um bom desenvolvimento em solos fracos e erodidos.

\section{Erva-mate}

A erva-mate é uma cultura que oferece mais de 400 anos de história nos países integrantes do Mercosul, além do Chile, Peru e Equador. O consumo de mate, principalmente sob a forma de chimarrão e de tererê, faz parte do hábito alimentar, da cultura, das relações comerciais e da caracterização política dos estados do Sul do Brasil (EMBRAPA, 1996).

Cerca de 600 espécies representam a família Aquifoliaceae, das quais 60 ocorrem no Brasil e à qual pertence a erva-mate. Recebeu o nome de Ilex paraguariensis em 1822, conforme classificação do naturalista francês August de Saint-Hillaire, do Museu de História Natural de Paris (DOSSA, 2000).

Segundo Mazuchowski (1989), a erva-mate é usada na forma de: a) bebidas (chimarrão, tererê, chá-mate, refrigerantes e sucos); b) insumos para alimentos (corante natural, conservante alimentar, sorvete, balas, bombons e caramelos, chicletes e gomas); c) medicamentos (compostos para tratamento de hipertensão, bronquite e pneumonia); d) higiene pessoal (bactericida e antioxidante hospitalar e doméstico, esterilizante, tratamento de esgoto e reciclagem de lixo urbano); e) produtos de uso pessoal (desodorantes, cosméticos, perfumes e sabonetes).

A erva-mate tem melhor aptidão em solos medianamente profundos a profundos, preferencialmente nas altitudes compreendidas entre 500 e 1500 metros, podendo ser encontrada em regiões situadas acima ou abaixo desses limites, de maneira mais esparsa (MAZUCHOWSKI, 1989).

A abrangência da área de ocorrência natural indica que a erva-mate é uma espécie florestal restrita a três países (Argentina, Brasil e Paraguai), estando presente em apenas cinco estados brasileiros: Mato Grosso do Sul, São Paulo, Paraná, Santa Catarina e Rio Grande do Sul (DOSSA et al. 2000).

A área ocupada pelos ervais no estado do Paraná abrange aproximadamente 283 mil hectares, dos quais cerca de $90 \%$ ainda são ervais nativos. Cerca de 51 mil propriedades rurais atuam com ervamate, em 180 municípios (EMBRAPA, 1996).

\section{Eucalipto}

O eucalipto é plantado atualmente, em quase todo o mundo, por ser uma planta que possui espécies adaptadas a diversas condições de clima e solo. A maioria das espécies plantadas no Brasil apresenta um crescimento rápido, produz grande quantidade de madeira e subprodutos e tem fácil adaptação. Para se ter uma idéia da diversificação das espécies, existem eucaliptos que se adaptam muito bem a regiões de temperaturas em torno de $35^{\circ} \mathrm{C}$ e outros que suportam um frio de até $18{ }^{\circ} \mathrm{C}$ abaixo de zero (BRANCO, 1999).

Os eucaliptos cobrem uma área de mais de 3 milhões de hectares que, apesar de estar concentrada principalmente nas regiões Sul e Sudeste do Brasil, apresenta plantios pulverizados em praticamente todo o território nacional. Os eucaliptos geralmente apresentam rápido crescimento e 
madeira de alta densidade básica. Ademais, a maior parte da madeira consumida no País é na forma de lenha ou carvão vegetal. Além da madeira e carvão, o eucalipto pode ser usado para a produção de mel, óleos essenciais, dormentes, celulose e papel, madeira serrada, mourões de cercas, postes, madeira para construções rurais, quebra-ventos etc (RODIGHERI, 1997).

Segundo Higa e Higa (2000), além dos eucaliptos, ainda não existem espécies florestais, nativas ou exóticas de outros gêneros, capazes de, no curto prazo, suprir a necessidade de madeira.

Pinus

A área plantada com o gênero Pinus ultrapassa os 2,5 milhões de hectares, constituindo-se na segunda espécie florestal mais plantada no Brasil. Da mesma forma que os eucaliptos, é uma espécie florestal de rápido crescimento e destina-se, principalmente, ao abastecimento de indústrias de papel e celulose, madeira para construções, laminados, resina, móveis e fins energéticos, na forma de lenha e/ou carvão, com significativa participação econômica no setor florestal brasileiro (RODIGHERI, 2000).

\section{Indicadores econômicos}

Valor presente líquido

Segundo Souza e Clemente (1999), o método do Valor Presente Líquido (VPL) é a técnica de análise de investimento mais conhecida e mais utilizada. O VPL, como o próprio nome diz, nada mais é do que a concentração de todos os valores esperados de um fluxo de caixa na data zero. Para tal, usa-se como taxa de desconto a Taxa Mínima de Atratividade (TMA) da empresa.

De acordo com Faro (1979), o Valor Presente Líquido de um projeto é a soma algébrica dos valores descontados, a determinada taxa de juros, do fluxo de caixa a ele associado.

Segundo Silva (1992), esse método é um dos mais utilizados na avaliação de investimentos, por obter o valor da produção em termos atuais, considerando uma taxa de juros, e por ser isento de falhas técnicas. A maior dificuldade na sua aplicação está na escolha de uma taxa de desconto apropriada para cada caso, além de apresentar problemas quando se trata da ordenação de projetos de investimento que possuem horizontes de planejamento diferentes.

A fórmula para o cálculo do Valor Presente Líquido (VPL) é:

$$
V P L=\sum_{j=0}^{n} R_{j}(1+i)^{-j}-\sum_{j=0}^{n} C_{j}(1+i)^{-j}
$$

Sendo: $\quad \mathrm{VPL}=$ valor presente líquido;

$\mathrm{Rj}=$ receitas no período $\mathrm{j}$;

$\mathrm{Cj}=$ custos no período $\mathrm{j}$;

$\mathrm{i}=$ taxa de desconto;

$\mathrm{j}=$ período de ocorrência do custo e da receita;

$\mathrm{n}=$ número total de anos do fluxo de caixa.

\section{Razão benefício/custo}

De acordo com Faro (1979), a Razão Benefício/Custo (RB/C) é o quociente entre o valor presente da seqüência de receitas e o valor presente da sucessão de custos. Se essa razão exceder a unidade, o valor presente líquido do investimento será positivo, indicando que o projeto é economicamente viável, sendo tanto mais interessante quanto mais a razão exceder a unidade.

A Razão Benefício/Custo, segundo Souza e Clemente (1999), é uma medida de quanto se ganha por unidade de capital investido. É, na verdade, um aprimoramento da taxa média de remuneração do capital investido no projeto e uma variante do método do Valor Presente Líquido. A hipótese implícita no cálculo da $\mathrm{RBC}$ é que os recursos liberados ao longo da vida útil do projeto seriam reinvestidos à taxa mínima de atratividade.

Algebricamente, pode-se representar a Razão Benefício/Custo pela seguinte expressão:

$$
R B / C=\frac{\sum_{j=0}^{n} \frac{R_{j}}{(1+i)^{j}}}{\sum_{j=0}^{n} \frac{C_{j}}{(1+i)^{j}}}
$$


Sendo: $\mathrm{RB} / \mathrm{C}=$ razão benefício/custo;

$\mathrm{Rj}=$ receitas do ano $\mathrm{j}$;

$\mathrm{Cj}=$ custos no ano $\mathrm{j}$;

$\mathrm{i}=$ taxa de desconto;

$\mathrm{j}$ = período de ocorrência do custo e da receita;

$\mathrm{n}=$ número total de anos do fluxo de caixa.

\section{Taxa interna de retorno}

A Taxa Interna de Retorno é definida como a taxa de desconto que faz com que o valor atualizado dos benefícios seja igual ao valor atualizado dos custos, sendo um método que depende exclusivamente do fluxo de caixa do sistema de produção. Constitui uma medida relativa que reflete o aumento no valor do investimento ao longo do tempo, tendo em vista os recursos demandados para produzir o fluxo de receitas (REZENDE; OLIVEIRA, 1995).

Para que se possa considerar um sistema de produção economicamente viável através da TIR, os resultados obtidos devem superar a taxa básica de remuneração ou taxa mínima de atratividade.

O cálculo da TIR é semelhante ao do Valor Presente Líquido, sendo que, no lugar de fixar uma taxa de desconto, esta iguala o VPL a zero.

$$
T I R=\sum_{t=0}^{n}\left(R_{j}-C_{j}\right)(1+i)^{-1}=0
$$

Sendo: $\quad$ TIR $=$ taxa interna de retorno;

$\mathrm{Rj}=$ receitas no período $\mathrm{j}$;

$\mathrm{Cj}=$ custos no período $\mathrm{j}$;

$\mathrm{i}=$ taxa de desconto;

$\mathrm{j}=$ período de ocorrência do custo e da receita;

$\mathrm{t}=$ tempo (anos).

\section{Custo de oportunidade da terra}

Segundo Berger (1985), a adição do Custo de Oportunidade da Terra aos resultados econômicos provocará um deslocamento proporcional em toda a extensão da função de receita total e como conseqüência no valor da mesma.

Lopez (1988) realizou uma análise econômica de custos e subsídios à produção de pinus na província de Missiones (Argentina) e considerou como custo da terra o custo de oportunidade pelo seu uso, isto é, uma remuneração de $6 \%$ ao ano sobre o valor do mercado.

Ribas (1989) baseou-se no valor de mercado da terra, que é determinado via comercialização da terra em determinada região pela oferta e demanda (preço de mercado).

\section{MATERIAL E MÉTODOS}

\section{Caracterização da área de estudo}

O estudo foi realizado em propriedades rurais do município de São José dos Pinhais, que se situa a $15 \mathrm{~km}$ do centro comercial de Curitiba, fazendo parte da Região Metropolitana de Curitiba, porém com autonomia política e econômica. Isso se deve à sua privilegiada posição geográfica e ao desenvolvimento dos seus setores agrícola e industrial. Possui uma superfície de 97.600 ha (IAP, 1999).

O município é parte integrante do primeiro planalto e possui uma altitude média de $900 \mathrm{~m}$, porém, existem diferenças de altitudes na região que variam de 300 a $1200 \mathrm{~m}$.

Os solos predominantes são classificados como latossolo vermelho-amarelo álico, horizonte A proeminente, textura argilosa, fase campo subtropical, relevo suave ondulado. Os solos das áreas aluvionares são classificados como solos orgânicos álicos, fase campo subtropical de várzea com relevo plano.

A vegetação original do município é classificada, segundo Maack (1968), como Mata de Araucária, e segundo Veloso et al. (1991), como Floresta Ombrófila Mista. Esse tipo de vegetação ocupa 
quase que inteiramente o planalto acima de $500 \mathrm{~m}$ de altitude nos estados do Paraná, Santa Catarina e Rio Grande do Sul. Sua principal característica é a alta freqüência de Araucaria angustifolia, que tem posição emergente no perfil da mata.

\section{Obtenção e tratamento dos dados}

As informações básicas para realização desta pesquisa foram obtidas por meio do Cadastro do Produtor Rural existente na prefeitura de São José dos Pinhais.

\section{Cadastro do produtor rural}

O questionário do Cadastro do Produtor Rural foi elaborado e aplicado pela Secretaria Municipal de Agricultura e Abastecimento da Prefeitura Municipal de São José dos Pinhais. Esse cadastro contém informações importantes da propriedade, que possibilitam um bom planejamento rural do município.

A Secretaria de Agricultura repassou, para a realização desta pesquisa, 980 questionários que haviam sido compilados. As informações contidas nesses questionários estavam na forma de banco de dados em Microsoft Access 2000. Os questionários foram analisados um a um, e aqueles que por ventura eram suspeitos de conter qualquer tipo de erro (de digitação, troca de unidades, etc.) foram eliminados.

Dos 980 questionários, foram eliminados 191, restando 789. Segundo a EMATER (2001), o município tem 3950 propriedades rurais. Sendo assim, foram abrangidas 19,97\% das propriedades rurais no município. Com as informações contidas no questionário, foi possível calcular algumas variáveis de interesse, entre elas a estrutura fundiária das propriedades rurais. Com base na classificação adotada pela EMATER, enquadraram-se as 789 propriedades em cinco classes distintas:

- Classe 1: 0,1 a 15 ha

- $\quad$ Classe 2: 15,1 a 30 ha

- $\quad$ Classe 3: 30,1 a 50 ha

- $\quad$ Classe 4: 50,1 a 100 ha

- $\quad$ Classe 5: acima de 100 ha

Com essa classificação, foi possível comparar os dados obtidos, relacionando-os com os dados fornecidos pela EMATER.

\section{Estimativa do perímetro das propriedades potenciais para plantios florestais}

Para estimar o perímetro médio das propriedades dentro de cada classe, utilizaram-se os dados gerados no cálculo da estrutura fundiária do município, da seguinte forma: foram somadas as áreas totais de todas as propriedades de cada classe, dividindo-se a área total pelo número de propriedades existentes na classe, ou seja, foi obtida uma área média dentro de cada classe. Adotou-se então o quadrado como figura geométrica, por apresentar um perímetro menor que o retângulo e maior do que a circunferência numa mesma área.

\section{Manejo de bracatinga, erva-mate, eucalipto e pinus nas divisas das propriedades}

Por se tratar de plantio em áreas limítrofes, o modelo de manejo proposto para a bracatinga foi o plantio de 2 linhas no perímetro da propriedade, utilizando-se o espaçamento de 3 x 2 metros, com corte raso aos 7 anos, com intenção de utilizar a madeira para fins energéticos.

Para facilitar o comparativo econômico com outras culturas florestais, foi calculada a rentabilidade econômica até os 21 anos, tendo o produtor que realizar novos plantios no $7^{\circ} \mathrm{e} 14^{\circ}$ anos.

$\mathrm{O}$ regime de manejo proposto para a erva-mate foi o plantio de 2 linhas de plantas em torno da propriedade, utilizando-se o espaçamento de $3 \times 2 \mathrm{~m}$. O sistema de poda adotado foi a poda de formação no $1^{\circ}$ e $2^{\circ}$ anos, e a poda de colheita a partir do $3^{\circ}$ ano até a idade de 21 anos.

Para o eucalipto, adotou-se o mesmo manejo adotado para bracatinga, ou seja, plantio de 2 linhas em torno da propriedade, utilizando-se o espaçamento de $3 \times 2 \mathrm{~m}$, com corte raso no $7^{\circ}$, no $14^{\circ}$ e no $21^{\circ}$ ano. Optou-se por conduzir a rebrota no $8^{\circ}$ e $15^{\circ}$ ano.

O manejo adotado para a produção de pinus é o único que se destoa dos demais. Com o objetivo de produzir madeira com alto valor agregado para serraria e laminação, utilizou-se um espaçamento de 4 x $2 \mathrm{~m}$, com corte raso aos 21 anos. Definiu-se que serão realizadas três podas durante os 21 anos, sendo a primeira realizada no $3^{\circ}$ ano, a segunda no $6^{\circ}$ ano e a terceira e última no $9^{\circ}$ ano. 


\section{Espaço físico para o plantio}

Para a realização do plantio das culturas propostas, adotou-se uma distância de $1 \mathrm{~m}$ antes da divisa da propriedade, com o intuito de evitar conflitos entre vizinhos, e $1 \mathrm{~m}$ depois da segunda linha plantada, para melhor manutenção da área plantada. Dessa forma, a largura do plantio em relação à divisa da propriedade totalizou 4 metros de largura, visto que foi adotado um espaçamento de 2 metros entre as linhas de plantio.

\section{Composição dos custos}

Os custos de implantação, estabelecimento e manutenção das essências florestais propostas para este trabalho foram calculados de acordo com o tamanho médio das propriedades classificadas no cálculo da estrutura fundiária do município. Consideraram-se, na composição dos custos, gastos com insumos, serviços e despesas gerais.

Atribuiu-se, para o preço das mudas, o valor praticado pelos viveiros florestais no estado do Paraná, de $\mathrm{R} \$ 0,10$ para a bracatinga, eucalipto e pinus, e de $\mathrm{R} \$ 0,15$ para as mudas de erva-mate. Consideraram-se $20 \%$ de replantio para todas as culturas.

Utilizou-se, para o formicida, o valor de $\mathrm{R} \$ 5,20$ o quilo, e para o adubo, $\mathrm{R} \$ 0,30$ o quilo.

Os valores utilizados para a mão-de-obra foram atrelados à produtividade ha/homem/dia. Considerou-se o salário mínimo de R $\$ 200,00$ e encargos sociais de $86 \%$ para calcular a diária de trabalho, de R $\$ 12,40$.

Tendo-se que a mão-de-obra regional é centrada principalmente na unidade familiar, não foram considerados gastos para fins administrativos.

A produtividade de cada atividade desenvolvida por cultura foi baseada na produtividade praticada por RODIGHERI (1997).

Considerou-se um raio médio de $20 \mathrm{~km}$ de deslocamento para o produtor buscar os insumos, pressupondo-se que o produtor irá realizar esse deslocamento duas vezes (uma vez no plantio e outra no replantio), totalizando uma distância de $80 \mathrm{~km}$. Atribuiu-se um custo de $\mathrm{R} \$ 0,45$ por $\mathrm{km}$ deslocado.

Estimou-se um gasto de monitoramento anual para as culturas, tempo em que o produtor irá monitorar o plantio nas áreas marginais. Atribuiu-se tempo diferenciado por tamanho de área plantada. Considerou-se também um gasto com despesas gerais, perdas eventuais que podem ocorrer nas culturas, causadas por pragas, entre outros fatores.

\section{Composição dos benefícios}

A produtividade da bracatinga foi baseada nos índices pesquisados pela EMBRAPA (1988) na região, de $87,5 \mathrm{~m}^{3} /$ ha, no final do sétimo ano. Considerou-se o preço utilizado pelo Departamento de Economia Rural e Alimentação do Estado do Paraná (DERAL, 2001), de R\$ 5,50 o m $\mathrm{m}^{3}$ de lenha estaleirada.

No cultivo do eucalipto, utilizou-se a mesma produtividade usada por Rodigheri (1997), de 231 $\mathrm{m}^{3} / \mathrm{ha}$, no final do sétimo ano. Utilizou-se o preço adotado pelo DERAL (2001), de R $\$ 8,00 \mathrm{o} \mathrm{m}^{3}$ de lenha estaleirada.

A produtividade da erva-mate em todos os anos de colheita foi a mesma utilizada pela EMATER (2001). O preço usado foi de $\mathrm{R} \$ 2,40$ a arroba colhida (DERAL, 2001).

Na cultura de pinus, utilizou-se a produtividade de $240 \mathrm{~m}^{3}$ por ha no final do $21^{\circ}$ ano, com 300 árvores remanescentes dos desbastes. O volume médio por árvore utilizado foi de $0,80 \mathrm{o} \mathrm{m}^{3}$ (EMATER, 2001). O preço usado foi de $\mathrm{R} \$ 25,00 \mathrm{o} \mathrm{m}^{3}$ de madeira em pé (DERAL, 2001).

\section{Indicadores econômicos}

Com o objetivo de apurar o resultado financeiro obtido no plantio de essências florestais no perímetro das propriedades rurais e comparar os benefícios e os custos da produção, foram feitas algumas avaliações para mostrar a eficiência do emprego do capital nos modelos considerados.

Como fonte para as avaliações, foram utilizados os custos anuais praticados, constituídos pelos gastos com mão-de-obra e insumos, e as receitas da comercialização dos produtos ofertados pelos plantios. As análises realizadas, portanto, restringiram-se à avaliação dos fatores de Fluxo de Caixa. Com isso, pretendeu-se determinar, com métodos quantitativos, as possíveis vantagens relativas de um modelo de plantio de uma essência florestal sobre o outro, em relação ao capital disponibilizado no decorrer do tempo (modelo de Fluxo de Caixa baseado em MALINOVSKI, 2002). 
Os instrumentos básicos de análise financeira usados para avaliar os resultados da pesquisa, em concordância com Reiche (1986) e Vieira Sobrinho (1995), foram o Valor Presente Líquido (VPL), a Razão Benefício/Custo (RB/C) e a Taxa Interna de Retorno (TIR).

A taxa de desconto adotada para o presente trabalho foi a taxa mínima de atratividade disponível no mercado (aplicações em poupança), que é de $6 \%$ ao ano.

Adotou-se uma taxa de $2 \%$ ao ano sobre o Custo de Oportunidade da Terra como forma de remuneração pelas áreas limítrofes a serem utilizadas pelos produtores para efetuar o plantio das essências florestais. Essa taxa seria como se o produtor arrendasse a terra para um terceiro, uma prática comum no meio rural. A taxa de $2 \%$ foi escolhida por se tratar de áreas que geralmente não são utilizadas pelos produtores para o plantio de culturas. Se o estudo fosse realizado em áreas comuns, não em áreas limítrofes, seria utilizada uma taxa de $6 \%$ ao ano.

Considerou-se, no fluxo de caixa, um valor de R\$10.000,00/ha para a terra. Esse valor é o preço médio praticado na região.

Realizaram-se projeções com e sem o Custo de Oportunidade da Terra para todas as culturas florestais propostas, com o intuito de analisar a influência desse fator no Valor Presente Líquido.

\section{RESULTADOS E DISCUSSÃO}

Os resultados mostram que das 789 propriedades analisadas, 607 propriedades enquadram-se na classe 1, ou seja, $76 \%$ das propriedades possuem área total entre 0,1 e 15 ha. Extrapolando essa porcentagem em relação ao número total de propriedades que existem no município (3.950), pode-se estimar que 3.039 propriedades possuem área inferior a 15 ha (Tabela 1).

Tabela 1. Estrutura fundiária das propriedades rurais em São José dos Pinhais - 2001.

Table 1. Size of rural propriety in São José dos Pinhais - 2001.

\begin{tabular}{lcccc}
\hline Classes & $\begin{array}{c}\text { Classificação } \\
\text { (ha) }\end{array}$ & $\begin{array}{c}\text { Número de } \\
\text { propriedades }\end{array}$ & $\begin{array}{c}\text { Área média } \\
\text { (ha) }\end{array}$ & $\begin{array}{c}\text { Número de propriedades } \\
\text { em relação ao total }\end{array}$ \\
\hline 1 & $0,1-15$ & 607 & 6,28 & 3039 \\
2 & $15,1-30$ & 122 & 22,20 & 611 \\
3 & $30,1-50$ & 38 & 36,93 & 190 \\
4 & $50,1-100$ & 32 & 62,22 & 110 \\
\hline Total & 789 & & 3950 \\
\hline
\end{tabular}

Fonte: Pesquisa de campo.

\section{Número de mudas a serem implantadas}

Com a obtenção do perímetro, calculou-se o número de mudas a serem plantadas em torno da propriedade dentro de cada classe. Na classe 1, em que a maioria das propriedades está inserida, seguindo o manejo proposto por espécie, com base nos respectivos espaçamentos, serão necessárias 800 mudas de bracatinga, erva-mate ou eucalipto, ou então 600 mudas de pinus (Tabela 2).

Tabela 2. Número de mudas a serem implantadas nas áreas limítrofes.

Table 2. Number of plant to be planted in bordering areas.

\begin{tabular}{lccccc}
\hline Classes & $\begin{array}{c}\text { Área média } \\
\text { (ha) }\end{array}$ & $\begin{array}{c}\text { Perímetro médio } \\
(\mathbf{m})\end{array}$ & $\begin{array}{c}\text { Área utilizada } \\
\text { para plantio } \\
\text { (ha) }\end{array}$ & \multicolumn{2}{c}{$\begin{array}{c}\text { Número de mudas }\left(\mathbf{m}^{\mathbf{2}}\right) \\
\text { Espaçamento (m) }\end{array}$} \\
\hline 1 & 6,28 & 1213 & 0,480 & 800 & $\mathbf{4 x 2}$ \\
2 & 22,26 & 2488 & 0,990 & 1650 & 600 \\
3 & 36,93 & 3039 & 1,211 & 2018 & 1238 \\
4 & 62,22 & 3786 & 1,509 & 2514 & 1886 \\
\hline Fonnyyy
\end{tabular}

Potencial econômico de reflorestamento em divisas de propriedades rurais

De acordo com os dados apresentados na Tabela 3, pode ser observado que o cultivo da bracatinga apresenta indicadores econômicos negativos em todos os tamanhos das áreas propostas para plantio. São evidenciados valores negativos de VPL e TIR, além de relação RB/C inferior a 1. Quando 
inserido o Custo de Oportunidade da Terra, o VPL quase triplica o valor negativo em todas as classes (verificar custos e receitas em MALINOVSKI, 2002).

Tabela 3. Indicadores econômicos para o cultivo da bracatinga em São José dos Pinhais - 2001 .

Table 3. Economics index for bracatinga culture in São José dos Pinhais - 2001.

\begin{tabular}{lccccc}
\hline Classes & $\begin{array}{c}\text { Tamanho da } \\
\text { área plantada }\end{array}$ & \multicolumn{4}{c}{ Indicadores econômicos } \\
\cline { 3 - 6 } & (ha) & VPL (RS) & RB/C & TIR & $\begin{array}{c}\text { VLP (R\$) com custo } \\
\text { de oport. da terra }\end{array}$ \\
\hline 1 & 0,480 & $-743,84$ & 0,3 & $-7 \%$ & $-1873,20$ \\
2 & 0,990 & $-1221,45$ & 0,4 & $-6 \%$ & $-3550,74$ \\
3 & 1,211 & $-1484,43$ & 0,4 & $-6 \%$ & $-4333,22$ \\
4 & 1,508 & $-1804,40$ & 0,4 & $-5 \%$ & $-5353,39$ \\
\hline
\end{tabular}

Fonte: Pesquisa de campo.

Atribui-se esse fraco desempenho ao baixo índice de produtividade da bracatinga na região, além do baixo preço oferecido pelo mercado de lenha de bracatinga.

$\mathrm{Na}$ avaliação da erva-mate, constatou-se que essa cultura apresenta os melhores índices de desempenho (Tabela 4). O VPL mostrou-se rentável em todos os tamanhos de áreas plantadas. A TIR mostrou que a atividade é capaz de superar a taxa mínima de atratividade e a $\mathrm{RB} / \mathrm{C}$ apresentou valor acima de 1 em todas as classes, ressaltando a boa capacidade remunerativa da cultura ervateira.

Inserido o custo de oportunidade da terra nos custos da cultura da erva-mate, verificou-se uma redução de $40 \%$ do VPL na primeira classe, $38 \%$ na segunda classe, $32 \%$ na terceira e quarta classes. Mesmo com essa redução, a erva-mate mantém-se como uma atividade economicamente rentável ao produtor rural.

Estudo realizado por Rodigueri (1997) mostra que o plantio solteiro da erva-mate (1 ha) em espaçamento $2 \times 2$ m pode atingir uma TIR de 43,84\%, índice mais elevado do que o apresentado nesta pesquisa, que foi de 22 e $24 \%$, dependendo do tamanho da área.

Tabela 4. Indicadores econômicos para o cultivo da erva-mate em São José dos Pinhais - 2001.

Table 4. Economics index for erva-mate culture in São José dos Pinhais - 2001.

\begin{tabular}{lccccc}
\hline Classes & $\begin{array}{c}\text { Tamanho da } \\
\text { área plantada }\end{array}$ & \multicolumn{4}{c}{ Indicadores econômicos } \\
\cline { 3 - 6 } & (ha) & VPL (R\$) & RB/C & TIR & $\begin{array}{c}\text { VLP (R\$) com custo } \\
\text { de oport. da terra }\end{array}$ \\
\hline 1 & 0,480 & 3278,13 & 2,3 & $22 \%$ & 1956,45 \\
2 & 0,990 & 7143,02 & 2,3 & $24 \%$ & 4407,92 \\
3 & 1,211 & 8748,02 & 2,3 & $24 \%$ & 5899,23 \\
4 & 1,508 & 10953,16 & 2,3 & $24 \%$ & 7404,17 \\
\hline
\end{tabular}

Fonte: Pesquisa de campo.

Dossa (2000) mostra resultado semelhante, em que o sistema de produção de erva-mate solteira foi o mais rentável, chegando a um VPL de R \$ 4,02/ha no período considerado de 21 anos.

A análise econômica realizada para a cultura de eucalipto (Tabela 5) mostra um VPL baixo quando comparado com as culturas de erva-mate e pinus, apesar de apresentar uma TIR acima da taxa mínima de atratividade e um $\mathrm{RB} / \mathrm{C}$ acima de 1; foi o sistema classificado em terceiro lugar, mostrando-se superior apenas ao cultivo da bracatinga.

Quando computado o custo da terra, a cultura do eucalipto mostrou-se economicamente inviável, com VPL negativo em todas as classes.

O pinus foi a cultura que atingiu o segundo melhor desempenho entre as culturas (Tabela 6), apresentando um VPL satisfatório para todas as classes de área, e foi a espécie que teve a maior $\mathrm{RB} / \mathrm{C}$ entre as culturas.

Observou-se que o custo da terra na cultura do pinus reduziu o VPL em $42 \%$ na primeira classe e $39 \%$ na segunda classe. Mesmo com essa redução, o cultivo do pinus manteve-se economicamente rentável. 
Tabela 5. Indicadores econômicos para o cultivo de eucalipto em São José dos Pinhais - 2001.

Table 5. Economics index for eucalipto culture in São José dos Pinhais - 2001.

\begin{tabular}{lccccc}
\hline \multirow{2}{*}{ Classes } & $\begin{array}{c}\text { Tamanho da } \\
\text { área plantada } \\
\text { (ha) }\end{array}$ & VPL (R\$) & RB/C & TIR & $\begin{array}{c}\text { VLP(R\$) com custo } \\
\text { de oport. da terra }\end{array}$ \\
\cline { 3 - 6 } & 0,480 & 295,93 & 1,5 & $11 \%$ & $-833,42$ \\
2 & 0,990 & 1083,77 & 1,9 & $16 \%$ & $-1406,21$ \\
3 & 1,211 & 1343,42 & 1,9 & $16 \%$ & $-1710,39$ \\
4 & 1,508 & 1705,66 & 1,9 & $16 \%$ & $-2085,90$ \\
\hline Fonte: Pesquisa de campo
\end{tabular}

Estudo realizado por Rodigueri (1997) mostra que o reflorestamento de pinus (1 ha) em espaçamento $2 \times 3 \mathrm{~m}$ pode atingir uma TIR de 17,09\%, resultado semelhante ao encontrado por esta pesquisa, utilizando-se o espaçamento de 4 × $2 \mathrm{~m}$.

Tabela 6. Indicadores econômicos para cultivo de pinus em São José dos Pinhais - 2001.

Table 6. Economics index for pine culture in São José dos Pinhais - 2001.

\begin{tabular}{lccccc}
\hline \multirow{2}{*}{ Classes } & $\begin{array}{c}\text { Tamanho da } \\
\text { área plantada }\end{array}$ & \multicolumn{3}{c}{ Indicadores econômicos } \\
\cline { 3 - 6 } & (ha) & VPL (R\$) & RB/C & TIR & $\begin{array}{c}\text { VLP (RS) com custo } \\
\text { de oport. da terra }\end{array}$ \\
\hline 1 & 0,480 & 2650,17 & 5,1 & $16 \%$ & 1520,82 \\
2 & 0,990 & 5850,45 & 6,4 & $17 \%$ & 3520,22 \\
3 & 1,211 & 7166,59 & 6,5 & $17 \%$ & 4316,86 \\
4 & 1,508 & 8982,39 & 6,6 & $17 \%$ & 5432,47 \\
\hline
\end{tabular}

Sawinski Júnior (2000) comenta que o pinus, comparado com outras culturas agroflorestais (eucalipto, erva-mate, feijão, milho e soja), apresentou uma $\mathrm{RB} / \mathrm{C}$ melhor, devido ao fato de ter uma baixa utilização de mão-de-obra, insumos e custos para o cultivo.

Fato importante a ser salientado é que todas as respostas econômicas apresentadas neste trabalho derivam diretamente do preço de mercado dos produtos aqui estudados. Caso haja variações na demanda desses produtos, com alterações de preços, as culturas podem também sofrer mudanças no desempenho econômico, melhorando ou piorando os rendimentos, de acordo com o grau de sensibilidade a esse fator.

\section{CONCLUSÕES}

Os resultados obtidos permitiram a formulação das seguintes conclusões:

- A erva-mate é a espécie florestal mais aconselhada para que o produtor obtenha uma receita extra na propriedade.

- O cultivo do pinus em áreas limítrofes também é aconselhado por apresentar rendimentos favoráveis para o produtor.

- O eucalipto foi classificado em terceiro lugar. Obteve um VPL baixo quando comparado com a ervamate e o pinus, porém, quando computado o Custo de Oportunidade da Terra torna-se economicamente inviável.

- O cultivo da bracatinga em áreas limítrofes não é recomendado, por ser antieconômico.

- O Custo de Oportunidade da Terra é um fator restritivo, independentemente do tamanho das áreas limítrofes projetadas.

- Em virtude do alto valor médio do ha na região, percebe-se que quando inserido o Custo de Oportunidade da Terra há uma diminuição significativa do VPL para todas culturas propostas independentemente do tamanho das áreas limítrofes projetadas.

- Desde que o proprietário da terra tenha uma fonte alternativa de renda e que haja um espaço disponível na sua propriedade, o reflorestamento em áreas de bordadura representa uma atividade opcional rentável ao produtor, pois demanda baixa quantidade de mão-de-obra para sua implantação e baixos custos de manutenção, podendo servir como fonte de capitalização de dinheiro a ser recuperado no médio e longo prazo. 


\section{REFERÊNCIAS}

AHRENS, S. Um modelo matemático para volumetria comercial de bracatinga (Mimosa scabrella Benth.). In: SEMINÁRIO SOBRE ATUALIDADES E PERSPECTIVAS FLORESTAIS, 4., 1981, Curitiba. Bracatinga uma alternativa para reflorestamento: Anais... Curitiba: EMBRAPA-URPFCS, 1981. p.77-90. (Documentos, n.5).

ANGELO, H. Cobertura florestal na pequena propriedade rural: uma alternativa para o desenvolvimento. Brasil Florestal, Brasília, n. 61, p. 37-41, 1987.

ANGELO, H. Valoração florestal de propriedades rurais em créditos de reposição florestal na área no Parque Nacional Grande Sertão Veredas. Brasília, [s.n.], 1999. 37p. Relatório técnico.

BAGGIO, A. J. Estudo sobre el sistema agroforestal tradicional de la bracatina (Mimosa scabrella Benth.) en Brasil: productividad, manejo de residuos y elaboration de compost. 242f. Tese- Universidad Politecnica de Madrid, Madrid, 1994.

BANCO DO BRASIL. Agronegócios. Disponível em: <http://www.bancodobrasil. com.br $>$ Acesso em: dez. 2000.

BARBOSA, T. Agricultura de baixa renda: questões de opcões de desenvolvimento. Revista Economia Rural, Brasília, v. 16, n. 3, p. 53-60, 1978.

BRANCO, E. F. Técnicas de plantio de eucalipto. Disponível em:. $<$ http://www.ipef.com.br $>$. Acesso em: 8 jul. 2000.

BEER F. J. Consideraciones basicas para el establecimiento de especies maderables em linderos. Agroflorestria en las Américas, Turriallba, v. 1, n. 1, p. 21-24, ene./mar. 1994.

BERGER, R. Aplicação de critérios econômicos para determinação da maturidade financeira de povoamentos de eucaliptos. 185f. Tese (Professor titular) - Departamento de Economia e Extensão, Setor de Ciências Agrárias, Universidade Federal do Paraná, Curitiba, 1985.

BIGARELLA, J. J. Segurança ambiental: uma questão de consciência e muitas vezes de segurança nacional. Brasília: Associação dos Diplomados da Escola Superior de Guerra, 1974. 66p.

CARVALHO, P. E. R. Comportamento da bracatinga (Mimosa scabrella Benth.) em plantios experimentais. In: SEMINÁRIO SOBRE ATUALIDADES E PERSPECTIVAS FLORESTAIS, 4., Bracatinga uma alternativa para reflorestamento. Curitiba, 1981. Anais...Curitiba, EMBRAPA-URPFCS, 1981. p.53-65.

CECCON, E. Diagnóstico da Importância do componente arbóreo nas pequenas e médias propriedades rurais em São João do Triunfo (PR). In: ENCONTRO BRASILEIRO DE ECONOMIA E PLANEJAMENTO FLORESTAL, 2., 1991, Colombo. Anais... Colombo: [s.n.], 1991, p.41-77.

DERAL, Secretaria de Agricultura e do Abastecimento do Estado do Paraná. Produção regional de bracatinga, erva-mate, eucalipto e pinus. Curitiba, 2001. tabelas.

DOSSA, D. et al. Aplicativo com análise de rentabilidade para sistemas de produção de florestas cultivadas e de grãos. Colombo: EMBRAPA-CNPF, 2000. 56p.

EMATER. Escritório regional. Relatório municipal da atividade florestal. São José dos Pinhais, 2001. não paginado.

EMBRAPA. Centro Nacional de Pesquisas de Florestas. Manual técnico da bracatinga (Mimosa scabrella Benth.). Colombo, 1988. 70 p. (Documentros, n.20).

EMBRAPA. Centro Nacional de Pesquisas Florestais. Caracterização de sistemas de uso da terra e propostas de ação para o desenvolvimento dos sistemas agroflorestais, Áurea-RS. Colombo, 1996. 39 p. (Documentros, n.29).

FARO, C. de. Elementos de engenharia econômica. 3 ed. São Paulo: Atlas, 1979. 328p. 
GIACOMINI, N. M. R. et al. O reflorestamento em pequena propriedade rural. In: ENCONTRO BRASILEIRO DE ECONOMIA FLORESTAL, 1., 1988, Colombo. Anais... Colombo: EMBRAPACNPF, 1988. v.2.627p.

HIGA, A. R.; HIGA, R. C. V. Indicação de espécies para reflorestamento. In: GALVÃO, A. P. M. Reflorestamento de propriedades rurais para fins produtivos e ambientais: um guia para ações municipais e regionais. Brasília: [s.n.], 2000. p.101-124.

HOSOKAWA, R. T. et al. Planejamento florestal: técnicas para manutenção da contribuição do setor florestal à economia nacional. Floresta, Curitiba, v. 15, n. 1-2, p. 4-7, 1984.

IAP. Gestão de resultados: Desenvolvimento florestal. Curitiba, 1999. 25p.

JANKOWSKY, I. P.; GALVÃO A. P. M. Principais usos da madeira de reflorestamento. In: GALVÃO A. P. M. Reflorestamento de propriedades rurais para fins produtivos e ambientais: um guia para ações municipais e regionais. Brasília: [s.n.], 2000. p.57-70.

LOPEZ, M. A. Análise econômica de custos e subsídios à produção de pinus spp. na província de Missiones - Argentina. 109f. Dissertação (Mestrado em Engenharia Florestal) - Setor de Ciências Agrárias, Universidade Federal do Paraná, Curitiba, 1988.

MAACK, R. Geografia física do Estado do Paraná. Curitiba: CODEPAR, 1968. 350p.

MAZUCHOWSKI, J. Z. Manual da erva-mate. Curitiba: Empresa Paranaense de Assistência Técnica e Extensão Rural, 1989. 104p.

MALINOVSKI, R. A. Reflorestamento em áreas limítrofes de propriedades rurais em São José dos Pinhais (PR): análise de percepção e de viabilidade econômica. 109f. Dissertação (Mestrado em Engenharia Florestal) - Setor de Ciências Agrárias, Universidade Federal do Paraná, Curitiba, 2002.

MILLER, R. L. Microeconomia: teoria, questões e aplicações. São Paulo: McGraw- Hill, 1981. 507p.

NAUTIYAL, J. C. Forest economics: principles and applications. Toronto: Canadian Scholar's, 1988. $58 \mathrm{p}$.

REICHE, C. E. Obtención y análisis práctico de datos económicos en sistemas agroforestales. In: OTS; CHATIE. Sistemas forestales: principios y aplicaciones en los tropicos. San José, 1986, p.601-610.

REICHMANN NETTO, F. Revegetalização de áreas marginais a reservatórios de hidroelétricas. In: SEMINÁRIO SOBRE ATUALIDADES E PERSPECTIVAS FLORESTAIS, 4., 1981, Curitiba. Anais... Curitiba: EMBRAPA-URPFCS, 1981. p.103-109.

REZENDE, J. L. P.; OLIVEIRA, A. D. Avaliação de projetos florestais. Viçosa, MG: Universidade Federal de Viçosa, $1995.47 \mathrm{p}$.

RIBAS, L. C. Estratégia econômica da reforma de povoamentos florestais Pinus spp. 112p. Dissertação (Mestrado em Engenharia Florestal) - Setor de Ciências Agrárias, Universidade Federal do Paraná, Curitiba, 1989.

RODIGHERI, H. R. Rentabilidade econômica comparativa entre plantios florestais e sistemas agroflorestais com erva-mate, eucalipto e pinus e as culturas do feijão, milho, soja e trigo. Colombo: EMBRAPA-CNPF, 1997. 36p. (Circular técnica, n.26).

RODIGHERI, H. R. Florestas como alternativa de aumento de emprego e renda na propriedade rural. Colombo: EMBRAPA-CNPF, 2000. 13p. (Circular técnica, n.42).

ROTTA, E.; OLIVEIRA, Y. M. N. Área de distribuição natural da bracatinga (Mimosa scabrella). In: SEMINÁRIO SOBRE ATUALIDADES E PERSPECTIVAS FLORESTAIS, 4., 1981, Curitiba. Anais... Curitiba: EMBRAPA-URPFCS, 1981. p.117-122.

SANTOS FILHO, A. As principais conseqüências do desenvolvimento e uso do solo no Estado do Paraná. Floresta, Curitiba, v. 11, n. 1, p. 1-12, 1980. 
SCHREINER, H. G. Pesquisa em agrosilvicultura no sul do Brasil: Resultados, perspectivas e problemas. In: SEMINÁRIO SOBRE SISTEMAS AGROFLORESTAIS NA REGIÃO SUL, 1., 1994, Colombo. Anais... Colombo: EMBRAPA-CNPF, 1994. 260p.

SAWINSKI JUNIOR, J. Rentabilidade econômica comparativa entre as culturas de pinus, eucalipto, erva-mate e as principais culturas agrícolas das microregião de Canoinhas-SC. 122f. Dissertação (Mestrado em Engenharia Florestal) - Setor de Ciências Agrárias, Universidade Federal do Paraná, Curitiba, 2000.

SILVA, R. P. Simulação e avaliação econômica de um programa plurianual de reflorestamento para fins de planejamento da empresa florestal. 56p. Dissertação (Mestrado) - Universidade Federal de Viçosa, Viçosa, MG,1992.

SOUZA, A.; CLEMENTE, A. Decisões financeiras e análise de investimentos: fundamentos, técnicas e aplicações. 3.ed. São Paulo: Atlas. 1999. 142p.

VELOSO, H. P. et al. Classificação da vegetação brasileira, adaptada a um sistema universal. Rio de Janeiro: IBGE. 1991. 123p.

VERDOLIN, H. A floresta e a conservação do solo. In: CONGRESSO FLORESTAL DE NOVA PRATA, 5., 1984, Rio Grande do Sul. Anais... Nova Prata: Governo do Estado do Rio Grande do Sul, 1984. v.1, p. $75-85$.

VIEIRA SOBRINHO, J. D. Matemática financeira. São Paulo: Atlas, 1995. 408p.

VINADÉ, L. F. F. et al. Causas do desmatamento em pequenas propriedades no Município de Frederico Westephalen-RS. Revista do Centro de Ciências Rurais, Porto Alegre, v. 10, n. 3, p. 83-277, 1980. 